\title{
Indicators of Functional Status for Primary Malignant Brain Tumour Patients
}

\author{
Miguel Bussière, Wilma Hopman, Andrew Day, Alicia Paris Pombo, \\ Teresa Neves, Francisco Espinosa
}

\begin{abstract}
Background: We compared the functional status and survival time of patients with malignant gliomas. Methods: This retrospective review included 143 patients diagnosed with malignant gliomas. Patients were grouped according to histopathological diagnosis. To measure functional status, patients were assigned a Karnofksy performance status (KPS) score at the time of presentation and at one, three, six, nine, 12 months and yearly intervals thereafter. Data were analyzed using descriptive methods as well as KruskalWallis tests, Chi-square tests, Log-Rank tests and Cox's proportional hazards modeling. Results: Eighty-four patients were male. The median age of patients was 63 years. One hundred and seven patients had a histopathological diagnosis of glioblastoma multiforme, 23 of anaplastic astrocytoma and 13 of anaplastic oligodendroglioma. Twenty-nine patients received aggressive multimodal treatment, 83 received intermediate treatment and the remaining 31 patients received conservative therapy. Significant treatment complications occurred in $33 \%$ of patients including four post-operative deaths. The anaplastic oligodendroglioma group had lower mortality and maintained better KPS scores over time, as did patients receiving full treatment. The most significant prognostic factors for functional status included age, pretreatment KPS, and type of treatment received. The most significant factors associated with time until death included age, severity of comorbidities, pretreatment KPS, presence of confusion, histopathological diagnosis and type of treatment received. Conclusion: In patients with malignant gliomas, younger age, better functional status at presentation and aggressive multimodal treatment were associated with improved longer-term functional status and survival. Confirmation of the effect of multimodal treatment on patient functional status would require a randomised controlled clinical trial.
\end{abstract}

RÉSUMÉ: Indices du pronostic de l'état fonctionnel chez les patients atteints de cancer primitif du cerveau. Introduction: Nous avons comparé l'état fonctionnel et la survie de patients atteints de gliomes malins. Méthodes: Cette revue rétrospective porte sur 143 patients porteurs d'un gliome malin. Ils ont été classés selon le diagnostic anatomopathologique. Un score était attribué à chaque patient selon l'indice fonctionnel de Karnofksy (IFK) à la consultation initiale et après 1, 3, 6, 9 et 12 mois de suivi et de façon annuelle par la suite. Les données ont été analysées au moyen de méthodes descriptives ainsi que du test de Kruskal-Wallis, du test du chi-carré, du test du log-rank et du modèle à hasard proportionnel de Cox. Résultats: Quatrevingt-quatre patients étaient des hommes et l'âge médian des patients était de 63 ans. Selon l'examen anatomopathologique, cent sept patients avaient un glioblastome multiforme, alors que chez 23 la tumeur était un astrocytome anaplasique et chez 13 un oligodendrogliome anaplasique. Vingt-neuf patients ont reçu une polythérapie agressive, 83 ont reçu un traitement intermédiaire et les 31 autres patients ont reçu un traitement conservateur. $33 \%$ des patients ont eu des complications importantes dues au traitement, dont quatre décès en période post-opératoire. Le groupe de patients atteints d'un oligodendrogliome an aplasique, de même que les patients ayant reçu un traitement agressif, avaient une mortalité plus basse et ont maintenu de meilleurs scores IFK pendant la période d'observation. Les facteurs qui prédisaient le mieux l'état fonctionnel étaient l'âge, l'IFK avant le traitement et le type de traitement reçu. Les facteurs les plus importants associés à la survie étaient l'âge, la sévérité des cormobidités, l'IFK avant traitement, le présence de confusion, le diagnostic anatomopathologique et le type de traitement reçu. Conclusion: Chez les patients atteints de gliomes malins, on observe un meilleur état fonctionnel et une survie plus longue chez ceux qui sont plus jeunes, qui ont un meilleur état fonctionnel au moment du diagnostic et qui reçoivent un traitement multimodal agressif. L'effet d'un traitement multimodal sur l'état fonctionnel des patients devra être confirmé par un essai clinique contrôlé randomisé.

Can. J. Neurol. Sci. 2005; 32: 50-56

In Canada and the United States combined, approximately 19,500 new cases of primary brain tumours occur each year, ${ }^{1,2}$ accounting for $2 \%$ of newly diagnosed cases of cancer. Half of these primary brain tumours are malignant or high grade gliomas, the most common being glioblastoma multiforme (GBM) 45-55\%, anaplastic astrocytoma (AA) $30-35 \%$ and anaplastic oligodendroglioma $(\mathrm{AO})<5 \%$. Recently, it was found
From the Department of Clinical Neurological Sciences, London Health Sciences Centre, University of Western Ontario (MB); Clinical Research Centre, Kingston General Hospital (WH, AD); Department of Community Health and Epidemiology (WH, APP, TN); Division of Neurosurgery, Department of Surgery (FE); Queen's University, Kingston, ON, Canada

Received November 6, 2000. Acceptedinfinalform SePtember 1, 2004. Reprint requests to: Wilma Hopman, Research Facilitator, Clinical Research Centre, Angada 4, Kingston General Hospital, Kingston, ON, Canada K7L2V7 
that the incidence of gliomas is rising in the elderly ${ }^{3-5}$ and that these tumours are more likely to be malignant in the elderly. The probability of malignancy is greater than $85 \%$ in patients over 60 years of age with an astrocytoma. ${ }^{5}$

Despite an aggressive multimodal approach to treatment of patients with malignant brain tumours,${ }^{6-9}$ the prognosis of these patients remains poor. Approximately 12,000 patients in Canada and the United States die of these tumours each year. ${ }^{1,2}$ Data obtained from clinical trials show that the median survival of patients with GBM is 0.9-1.2 years, AA is 2.8-4.2 years and AO is 6.3-7.3 years. ${ }^{9,10}$ These survival times are likely overestimated due to the selection bias associated with recruitment of patients with better functional status into clinical trials. The median survival of patients greater than 60 years old with poor performance status at the time of presentation is approximately three to four months. ${ }^{11-14}$ Several factors that favor longer survival have been identified from the clinical trials data, including age, tumor histopathology, patient functional status and extent of surgical resection. ${ }^{13,15}$

Although much research has been dedicated to examining effects of therapy on survival time of patients with malignant gliomas, there have been relatively few studies examining patient functional status. Collectively, however, these studies have shown that the functional status of patients with malignant gliomas is sustained or slightly improved after treatment. ${ }^{16-21}$ Functional status is maintained for $60-80 \%$ of the patient's lifespan followed by a period of rapid functional decline and death usually within two to three months after the decline has begun. ${ }^{16-21}$ These studies have examined the effect of one treatment modality on functional status, including surgical resection, radiotherapy or chemotherapy. Since a multimodal approach is currently used in the treatment of malignant gliomas, we were interested in determining whether the type of treatment received was a significant predictor of the functional status and mortality of typical patients with malignant gliomas that may or may not be represented in clinical trials.

Four approaches were used to examine this question. First, we described the sample and reported the percent of patients alive and the percent functionally independent by histopathological diagnosis from admission to follow-up at regular intervals. Next, we examined the change in Karnofksy performance status (KPS) scores in the first year of follow-up by diagnosis. Third, we identified factors associated with survival with a functionally independent status. Finally, we determined the factors associated with survival time.

\section{METHODS}

All patients diagnosed with malignant gliomas at Kingston General Hospital and Hotel Dieu Hospital between January 1, 1990 and June 30, 1999 were included in this retrospective observational analysis. Diagnosis was based on pathology reports and on radiographic appearance. Twenty-two patients were diagnosed with GBM on the basis of radiographic findings alone and were included in the study given the low risk $(<4 \%)$ of misdiagnosis. ${ }^{22}$ Pathology reports were available for the remainder of patients. Patients were excluded from the study if a date of death was not available for those who had died, or if the patients' immediate family did not give consent.
Data were obtained from patient charts at the Kingston General Hospital, Hotel Dieu Hospital, and the Kingston Regional Cancer Center, as well as from phone interviews. Data included age, gender, symptoms at presentation, duration of symptoms (weeks), delay in presentation, histological diagnosis, location and size of tumour and KPS. ${ }^{23}$ Comorbid conditions were identified, and the presence of and severity of the comorbid conditions was collected into a single variable of 'none', 'mild/moderate' and 'severe'. The KPS scores were assigned at first presentation and at one, three, six, nine and 12 months and yearly intervals thereafter up to four years. The KPS scores were assigned on the basis of information obtained from admission records, operative reports, clinic reports, daily charting and discharge summaries. A KPS score of 0 indicates death, 70 or above indicates a functionally independent status and 100 indicates the patient is fully functional with no deficit. ${ }^{23}$ The KPS scale was used due to its simplicity, wide spread use, reliability and validity. ${ }^{24,25}$

Treatment groups were defined as follows: patients in the "conservative" treatment group received dexamethasone \pm biopsy and patients in the "full" treatment group received dexamethasone, surgery, radiotherapy (>50 Gray) and adjuvant chemotherapy, either PCV (procarbazine, lomustine, vincristine) and/or tamoxifen. Patients in the "intermediate" treatment group received treatment regimens that did not meet the criteria for inclusion into either the conservative or full treatment groups as described (greater than conservative but less than full treatment).

\section{Statistical analysis}

Patients were initially described in terms of sociodemographic characteristics and functional status at admission (pretreatment). Kruskal-Wallis and Chi-square tests were used to compare the baseline characteristics of the three histopathological groups. The number of patients alive and the number functionally independent (KPS $\geq 70)$ at each follow-up time were described. Between group differences in median survival time and median time with KPS $\geq 70$ were examined using the Log-Rank test for equality of groups. To assess median survival time, those still alive at the end of the study or those lost to follow-up were censored at the end of the study or at the time of their last known follow-up. Patients with initial KPS scores below 70 were excluded from the analysis of length of time with functional independence. To determine the joint effect of potential prognostic factors, Cox's proportional hazards regression models were developed for both time until KPS dropped below 70, and for time until death. The models included variables for histopathological diagnosis and treatment as well as any additional covariates that remained significant at $\mathrm{p} \leq 0.1$ in the combined model. Backwards selection was used to identify significant covariates.

\section{RESULTS}

Of 151 patients initially identified with malignant gliomas, eight were excluded due to an unavailable death date or inability to reach the family for consent. The overall characteristics of the patients are presented in Table 1 . They ranged in age from eight to 86 years old with a median of 63 years, and $58.7 \%$ were male. One hundred and seven had a pathological diagnosis of GBM, 23 of AA and 13 of AO. An equal proportion of tumours were located in each hemisphere. 
Table 1: Patient Characteristics Overall and by Histopathological Diagnosis

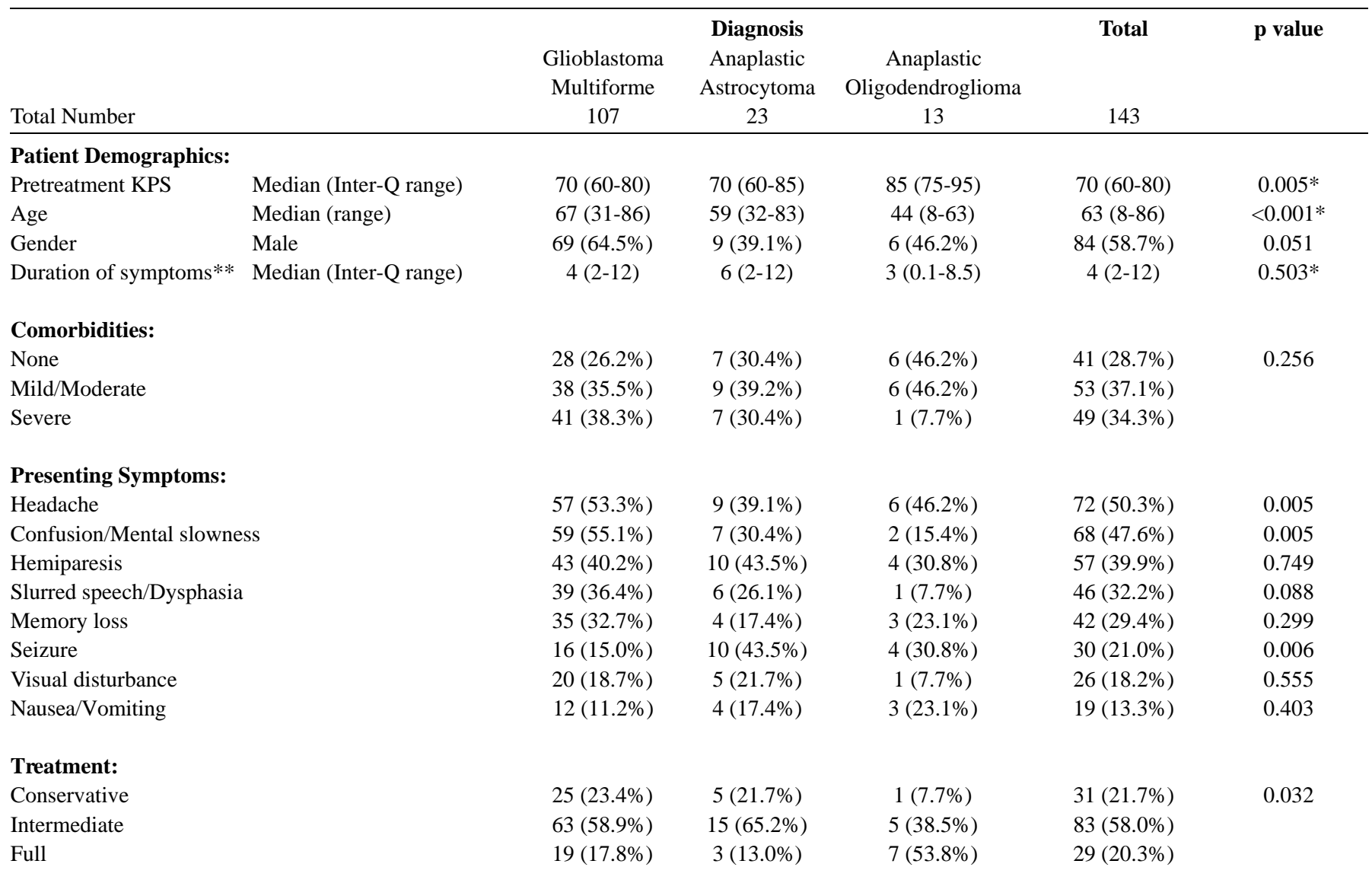

* Kruskall-Wallis p-value for comparing the three treatment groups. All others are Pearson Chi-square p-values for comparing the three treatment groups. Inter-Q = inter-quartile range. $* *=$ weeks

Twenty-nine patients received full treatment, 83 intermediate treatment and 31 conservative treatment. The majority of the GBM and AA groups received intermediate treatment, while the majority of the AO group received full treatment $(\mathrm{p}=0.032)$. Four patients died postoperatively. Significant treatment complications occurred in $33 \%$ of patients, including infection, increased or new focal neurological deficit, decreased level of consciousness, seizure and deep venous thrombosis/pulmonary embolism. There were significant differences in age and pretreatment KPS scores between the three diagnostic groups $(\mathrm{p}<0.01$ for both). The gender distribution approached significance, with men representing the majority of the GBM group and the minority of the AO group. There were no significant differences between the three groups in the severity of comorbidities, but there were significant differences in the presenting symptoms, most notably for headache, confusion/mental slowness and seizures $(\mathrm{p}<0.01$ for all). The majority of the tumours were in the temporal lobe $(17.5 \%)$, parietal lobe $(14.0 \%)$, parietotemporal lobe $(12.6 \%)$ and the parieto-occipital lobe $(8.4 \%)$.

KPS and Mortality between Pretreatment and Follow-up

Table 2 describes the number of patients alive at each time point by histopathological diagnosis, as well as those surviving with a good functional status (KPS $\geq 70$ ). One hundred and eighteen patients died as a consequence of their malignancy during the study period. Twenty were lost to follow-up or had insufficient information to generate a KPS score. Fifty-six patients had an initial KPS score below 70, while 87 survived for a period of time with a KPS score equal to or above 70 . Of the latter, 10 were in the conservative, 53 in the intermediate and 24 in the full treatment group. Most of those receiving conservative therapy had died by six months, with two surviving and one lost to follow-up. Both the GBM and the AA groups showed high mortality and large drops in KPS scores over time. Of the eight patients surviving to four years of follow-up, five had a histopathological diagnosis of AO, two of AA and one of GBM, all of which had received intermediate or full treatment. Six of these patients were functionally independent, three with AO, two with AA and one with GBM.

Table 3 contains the changes in KPS over time by diagnosis. Only changes over the first year are presented, as the sample size becomes quite small beyond that time. Patients were assigned KPS scores of 0 at the time of death, contributing to the large mean declines over time as more patients died. Mean changes are 
Table 2: Number and Percent of Patients Alive and Functionally Independent by Diagnosis over Time

\begin{tabular}{|c|c|c|c|c|c|c|}
\hline Month & \multicolumn{2}{|c|}{$\begin{array}{l}\text { Glioblastoma multiforme } \\
\qquad(\mathrm{n}=107)\end{array}$} & \multicolumn{2}{|c|}{$\begin{array}{l}\text { Anaplastic astrocytoma } \\
\qquad(\mathbf{n}=\mathbf{2 3})\end{array}$} & \multicolumn{2}{|c|}{$\begin{array}{l}\text { Anaplastic oligodendroglioma } \\
\qquad(\mathrm{n}=13)\end{array}$} \\
\hline Pre & $61(57.0 \%)$ & $107(100.0 \%)$ & $14(60.9 \%)$ & $23(100.0 \%)$ & $12(92.3 \%)$ & $13(100.0 \%)$ \\
\hline 3 & $33(30.8 \%)$ & $60(58.3 \%)$ & $8(34.8 \%)$ & $17(73.9 \%)$ & $10(76.9 \%)$ & $13(100.0 \%)$ \\
\hline 6 & $24(22.4 \%)$ & $37(37.4 \%)$ & $6(26.1 \%)$ & $11(50.0 \%)$ & $8(61.5 \%)$ & $10(90.9 \%)$ \\
\hline 9 & $15(14.0 \%)$ & $26(26.5 \%)$ & $6(26.1 \%)$ & $9(40.9 \%)$ & $8(61.5 \%)$ & $10(90.9 \%)$ \\
\hline 36 & $2(1.9 \%)$ & $3(3.1 \%)$ & $2(8.7 \%)$ & $2(10.5 \%)$ & $5(38.5 \%)$ & $5(55.6 \%)$ \\
\hline 48 & $1(1.0 \%)$ & $1(1.0 \%)$ & $2(8.7 \%)$ & $2(10.5 \%)$ & $3(23.1 \%)$ & $5(55.6 \%)$ \\
\hline
\end{tabular}

* Percentages for KPS $\geq 70$ (K70) are based on the total for each diagnostic sample. Percentages for those known to be alive have been adjusted for those lost to follow-up. As a result, the percentages for the same value may not be equal.

Table 3: Change in Karnofsky Scores from Pretreatment to Follow-up in the First Year

\begin{tabular}{|c|c|c|c|c|c|c|}
\hline \multirow[t]{2}{*}{ Diagnosis } & & \multirow[t]{2}{*}{ Alive } & \multirow{2}{*}{$\begin{array}{c}\text { Mean } \\
\text { Change }\end{array}$} & \multirow{2}{*}{$\begin{array}{l}\text { Standard } \\
\text { Deviation }\end{array}$} & \multicolumn{2}{|c|}{$95 \% \mathrm{CI}$} \\
\hline & & & & & Lower & Upper \\
\hline \multirow[t]{3}{*}{ One Month } & Glioblastoma multiforme & 96 & -11.34 & 18.62 & -14.93 & -7.75 \\
\hline & Anaplastic astrocytoma & 22 & -6.52 & 17.15 & -13.94 & 0.89 \\
\hline & Anaplastic oligodendroglioma & 13 & -2.69 & 28.62 & -19.99 & 14.60 \\
\hline \multirow[t]{3}{*}{ Three Months } & Glioblastoma multiforme & 60 & -30.28 & 29.61 & -36.07 & -24.49 \\
\hline & Anaplastic astrocytoma & 17 & -23.36 & 30.87 & -37.05 & -9.67 \\
\hline & Anaplastic oligodendroglioma & 13 & 0.00 & 29.51 & -17.83 & 17.83 \\
\hline \multirow[t]{3}{*}{ Six Months } & Glioblastoma multiforme & 37 & -41.34 & 30.88 & -47.50 & -35.19 \\
\hline & Anaplastic astrocytoma & 11 & -38.22 & 36.67 & -54.49 & -21.97 \\
\hline & Anaplastic oligodendroglioma & 10 & -4.09 & 38.39 & -29.88 & 21.70 \\
\hline \multirow[t]{3}{*}{ Nine Months } & Glioblastoma multiforme & 26 & -49.80 & 29.42 & -55.71 & -43.91 \\
\hline & Anaplastic astrocytoma & 9 & -42.59 & 35.93 & -58.52 & -26.66 \\
\hline & Anaplastic oligodendroglioma & 10 & -4.54 & 39.08 & -30.80 & 21.71 \\
\hline \multirow[t]{3}{*}{ Twelve Months } & Glioblastoma multiforme & 19 & -55.96 & 27.37 & -61.45 & -50.47 \\
\hline & Anaplastic astrocytoma & 6 & -48.86 & 34.63 & -64.22 & -33.51 \\
\hline & Anaplastic oligodendroglioma & 9 & -7.27 & 39.77 & -33.99 & 19.45 \\
\hline
\end{tabular}

Pretreatment scores were subtracted from each time point so that negative values equate to declines. All but one of the between-group differences were highly significant at $\mathrm{p} \leq 0.005$ (histological diagnosis at one month $\mathrm{p}=.222$ ). $\mathrm{CI}=$ confidence intervals

\section{Table 4: Overall Survival Times and Time with Functional Independence}

\begin{tabular}{|c|c|c|c|c|}
\hline Diagnosis & $\mathrm{N}$ with a known event* & $\begin{array}{c}\text { Median Overall } \\
\text { Survival Time } \\
(95 \% \mathrm{CI})\end{array}$ & $\begin{array}{c}\text { N with Baseline } \\
\quad K P S \geq 70\end{array}$ & $\begin{array}{c}\text { Median time } \\
\text { with } \mathrm{KPS} \geq 70^{* * *} \\
(95 \% \mathrm{CI})\end{array}$ \\
\hline Glioblastoma multiforme & $94(88 \%)$ & $4.2(3.2-7.0)$ & $61(57 \%)$ & $1.8(0.8-11.0)$ \\
\hline Anaplastic astrocytoma & $18(78 \%)$ & $5.8(3.8-11.9)$ & $14(61 \%)$ & $1.4(1.0-11.0)$ \\
\hline \multirow[t]{2}{*}{ Anaplastic oligodendroglioma } & $6(46 \%)$ & $49.0(15.0-\infty)$ & $12(92 \%)$ & $23.5(12.0-\infty)$ \\
\hline & & $\begin{array}{l}\text { gnosis differences significant } \\
\text { at } p<.0001\end{array}$ & & $\begin{array}{l}\text { Diagnosis differences } \\
\text { significant at } \mathrm{p}=.012\end{array}$ \\
\hline
\end{tabular}

Significance testing done by the Log-Rank test; $*$ Those still alive and those lost to follow-up are censored; ** For the subset of patients with initial $\mathrm{KPS} \geq 70$. CI $=$ confidence intervals 
Table 5: Multivariable Model of Predictors for Time to KPS < 70 and Time to Death

\section{Variable}

Age (per 10 years)

Pretreatment KPS

Severity of comorbidities

Confusion

Anaplastic astrocytoma

versus Glioblastoma multiforme

Anaplastic oligodendroglioma

versus Glioblastoma multiforme

Conservative versus Intermediate

Treatment

Full versus Intermediate Treatment

Predictors for Time to KPS $<70$

P-value

Hazard
Ratio

$<.0001$

$$
1.74
$$

0.55

\section{5\% Hazard Ratio \\ Confidence Limits \\ $1.37-2.21$}

0.0004

$0.40-0.77$

(1)

0.0920

0.54

$0.27-1.11$

0.48

$0.21-1.11$

3.24

$1.44-7.28$

0.0045

0.3917

$0.45-1.37$

0.78

Predictors for Time to death

Global test of treatment modality difference after controlling for other significant covariates $\mathrm{p}=0.01$

presented, rather than median changes, as the median value dropped to 0 very quickly for some groups. The glioblastoma group showed the largest and fastest decline. The AO group showed a small mean decline at one month, no change at three months and small declines beyond that over time.

\section{Survival time and time with an independent functional status}

Table 4 contains the information regarding overall median survival time. Median survival time was 4.2 months for the GBM group, followed by the AA group at 5.8 months and the AO group at 49.0 months. Figure 1 contains the Kaplan-Meier survival curve for the three histopathological diagnosis groups for the first two years following treatment. Although all the

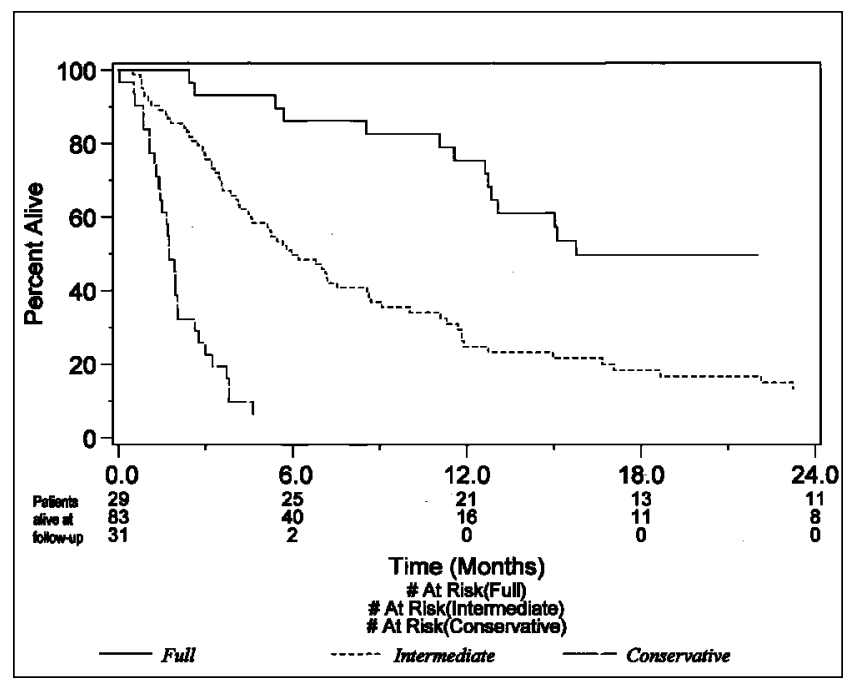

Figure 1: Overall Survival by Histopathological Diagnosis available data were used in the analysis, only the first two years are displayed in the figures. The survival curve clearly shows the different survival rates for the three groups, and the Log Rank test indicates that the difference is statistically significant $(\mathrm{p}=$ .0001).

Table 4 also contains the median length of time with a KPS $\geq$ 70 following treatment. Length of time with functional independence was the lowest for the GBM (1.8 months) and AA groups (1.4 months) as compared to the AO group (23.5 months). The Kaplan-Meier curve for functional independence is contained in Figure 2, and clearly shows the different rates of deterioration for the three groups, which is significant using the Log Rank test $(p=.006)$. It should be noted that only 87 of the patients contributed to the analysis of time with functional

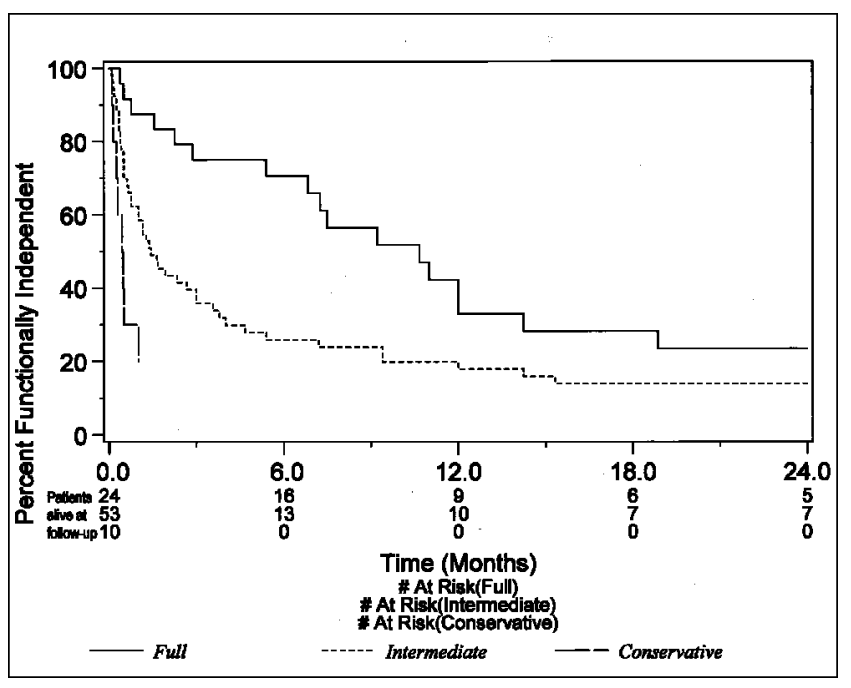

Figure 2: Time Functionally Independent (Subgroup with Initial KPS $\geq 70, n=87$ ) by Histopathological Diagnosis 
independence, as inclusion required a pretreatment KPS score $\geq 70$.

Table 5 shows the multivariable model of predictors of survival with an independent functional status (KPS $\geq 70$ ), and predictors of overall survival time. Variables with hazard ratios greater than one are associated with an increased risk, or equivalently, a shorter time until loss of functional independence or death. Histopathological diagnosis was included in the models and age, gender, pretreatment KPS, delay in presentation, the presenting symptoms listed in Table 1, tumour size, hemisphere, single or multifocal, severity of comorbid conditions and treatment received (conservative, intermediate or full) were offered as candidates for adjustment.

For survival with an independent functional status, the most significant predictors were age (older age was associated with faster decline) and pretreatment KPS (higher KPS scores had better outcomes). In terms of treatment groups, patients in the conservative treatment group had the shortest time with KPS $>70$. There was a substantially higher risk in the conservative group compared to the intermediate group $(\mathrm{HR}=3.2 ; \mathrm{p}=0.005)$, but the difference between the full treatment and intermediate group was not as clear $(\mathrm{HR}=0.78 ; \mathrm{p}=0.39)$. Histopathological diagnosis was not a significant predictor for survival with an independent functional status in our model.

For survival time, age was again a very significant predictor, with older patients surviving a shorter time. Severity of comorbid conditions and the presence of confusion were both associated with a shorter survival time. Better pretreatment KPS scores were moderately associated with longer survival. Both the AAand the AO groups had a longer survival time than the GBM group ( $\mathrm{p}=0.055$ and $\mathrm{p}=0.042$ respectively). Conservative treatment remained strongly associated with shorter survival time as compared to intermediate treatment $(\mathrm{HR}=4.3 ; \mathrm{p}<0.0001)$, but there was only moderate evidence of a survival advantage for the full treatment compared to the intermediate treatment $(\mathrm{HR}=0.62 ; \mathrm{p}=0.09)$.

\section{Discussion}

Numerous studies have shown that histopathological diagnosis, age, functional status at presentation and aggressive treatment, ${ }^{13,15}$ including gross surgical resection, ${ }^{19}$ high dose radiotherapy ${ }^{26}$ and adjuvant chemotherapy, ${ }^{27-29}$ improve the survival time of patients with malignant gliomas. The results from this study suggest that these factors predict improved patient functional status, in addition to survival. Independent functional status and survival were highest for the full treatment group, intermediate for patients receiving intermediate treatment and the lowest for the conservative group. The association between treatment and survival, and between treatment and functional status, was independent of factors such as age, pretreatment KPS and histological diagnosis. The difference between treatment groups in terms of time of functional independence remained statistically significant even after these other factors were controlled for, as did the between-group differences in overall survival. Although the advantage of intermediate treatment over conservative treatment remained substantial even after controlling for significant prognostic factors, the advantage of full treatment over intermediate treatment was not as clear. These findings are consistent with those of previous studies that have shown that the functional status of patients with malignant gliomas is sustained or slightly improved after treatment. ${ }^{16-21}$

There were several limitations to this study. Data were collected and KPS scores were assigned retrospectively, lessening the certainty of the primary endpoint of functional independence (KPS $\geq 70$ ). Despite this limitation, KPS was still found to be a significant predictor of survival (Table 7), as has been shown in numerous other studies. ${ }^{13,15}$ A second limitation of this study is that the three tumour types, GBM, AA and AO were grouped together for some of the analyses. It is well-known that AO tumours are sensitive to chemotherapy, especially those harbouring the chromosomal deletions $1 \mathrm{p}$ and $19 \mathrm{q} \cdot{ }^{30-32}$ Although there were few patients with AO included in this study (13 patients), the more favourable prognosis of patients with this tumour type may have biased the results in favour of an effect of treatment on functional status and survival. Indeed, AO patients survived and maintained functional independence longer than patients with GBM or AA (Table 3-5). Causality cannot be inferred from these data, as this study was observational in design and a randomised controlled clinical trial would be required to confirm these observations. Patients were not randomly assigned to the treatment groups, but were assigned on the basis of their pretreatment characteristics such as functional status, age, tumour type and prognosis, and these data suggest that the three treatment groups were already very different at baseline.

In the last several years, temazolamide has largely replaced PCV as adjuvant chemotherapy for the treatment of recurrent malignant gliomas, with the exception of AO. ${ }^{33-35}$ Temozolamide therapy is more easily tolerated and is associated with better health-related quality of life assessments versus procarbazine. ${ }^{33,34}$ Temozolamide was not utilized at the time of this study. Its use as adjuvant chemotherapy may have resulted in a more significant association of treatment and functional status.

Several groups are developing more convenient methods of assessing patient quality of life in patients with brain tumours. $^{36,37}$ The dimensions of quality of life include physical, psychological, emotional, social, financial, spiritual and cultural factors. The Karnofsky scale only estimates the physical/ functional status of patients. It has also been shown that KPS scores > 90 are not sensitive to more subtle functional and quality of life changes. ${ }^{36,38}$ More recent randomized clinical trials $^{33,34}$ are incorporating health-related quality of life assessments as a primary or secondary end-point.

This study suggests that aggressive multimodal treatment is a significant predictor of longer time with functional independence, as well as longer overall survival time. Confirmation of this result would require examining the effect of multimodal treatment on patient functional status in a randomised controlled clinical trial. This study also demonstrates that it is possible to systematically assess factors associated with these outcomes. It is important to note, however, that despite multimodal aggressive therapy, the improvement in survival and functional status associated with treatment is measured in terms of months and that a significant proportion of this time may be spent in hospital. In making decisions regarding treatment, therefore, it is particularly important to respect a patient's values and wishes 
and to give thought to the patient's potential life expectancy and functional improvement.

\section{REFERENCES}

1 Gaudette LA, Lee J. Statistics Canada. Cancer Incidence in Canada, 1969-1993. Ottawa: Health Statistics Division, Catalogue 82566-XPB. Occasional, Ottawa, April 1997.

2 Chen VW, Howe HL, Wu XC, Hotes JL, Correa CN (Eds). Cancer in North America, 1993-1997. Volume One: Incidence, Volume Two: Mortality. Sacramento, CA: North American Association of Central Cancer Registries, April 2000.

3 Desmeules M, Mikkelson T, Mao Y. Increasing incidence of primary malignant brain tumours: Influence of diagnostic methods. J Natl Cancer Inst 1992; 84: 442-445.

4 Riggs JE. Rising primary malignant brain tumor mortality in the elderly. Arch Neurol 1995; 52: 571-575.

5 Fernandez PM, Brem S. Malignant brain tumours in the elderly. Clin Geriatr Med 1997; 13: 327-338.

6 Fine HA. The basis for current treatment recommendations for malignant gliomas. J Neurooncol 1994; 20: 111-120.

7 Forsyth PAJ, Cairncross JG. Treatment of malignant glioma in adults. Curr Opin Neurol 1995; 8: 414-418.

8 Whittle IR. Management of primary malignant brain tumours. J Neurol Neurosurg Psychiatry 1996; 60: 2-5.

9 Chamberlain MC, Kormanik PA. Practical guidelines for the treatment of malignant gliomas. West J Med 1998; 168: 114-200.

10 Levin VA. Neuro-oncology. an overview. Arch Neurol 1999;56:401-403.

11 Whittle IR, Denholm SW, Gregor A. Management of patients aged over 60 years with supratentorial glioma: lessons from an audit. Surg Neurol 1991; 36: 106-111.

12 Halperin EC. Malignant gliomas in older adults with poor prognostic signs. Getting nowhere, and taking a long time to do it. Oncology 1995; 9: 229-234.

13 Curran WJ, Scott SB, Horton J, et al. Recursive partitioning analysis of prognostic factors in three radiation therapy oncology group malignant glioma trials. J Natl Cancer Inst 1993; 85: 704-710.

14 Mohan DS, Suh JH, Phan JL, et al. Outcome in elderly patients undergoing definitive surgery and radiation therapy for supratentorial glioblastoma multiforme at a tertiary care institution. Int J Radiat Oncol Biol Phys 1998; 42: 981-987.

15 Medical Research Council Brain Tumour Working Party. Prognostic factors for high-grade malignant glioma: development of a prognostic index. J Neurooncol 1990; 9: 47-55.

16 Shapiro WR, Young DF. Chemotherapy of malignant glioma. A controlled study of chemotherapy and irradiation. Arch Neurol 1976; 33: 494-500.

17 Hochberg FH, Linggood R, Wolfson L, Baker WH, Kornblith P. Quality and duration of survival in glioblastoma multiforme. Combined surgical, radiation, and lomustine therapy. JAMA 1979; 241: 1016-1018.

18 Shapiro WR. Treatment of neuroectodermal brain tumours. Ann Neurol 1982; 12: 231-237.

19 Ammimrati M, Vick N, Liao Y, Ciric I, Mikhael M. Effect of the extent of surgical resection on survival and quality of life in patients with supratentorial glioblastomas and anaplastic astrocytomas. Neurosurgery 1987; 21: 201-206.

20 Leibel SA, Gutin PH, Wara WM, et al. Survival and quality of life after interstitial implantation of removable high activity Iodine-
125 sources for the treatment of patients with recurrent malignant gliomas. Int J Radiat Oncol Biol Phys 1989; 17: 1129-1139.

21 Sachsenheimer W, Piotrowski W, Bimmler T. Quality of life in patients with intracranial tumours on the basis of Karnofsky's performance status. J Neurooncol 1992; 13: 177-181.

22 Choksey MS, Valentine A, Shawdon H. Computed tomography in the diagnosis of malignant brain tumours: do all patients require biopsy? J Neurol Neurosurg Psychiatry 1989; 52: 821-825.

23 Karnofsky DA. The clinical evaluation of chemotherapeutic agents in cancer. In: Macleod CM, Burchenal JH (Eds). Evaluation of Chemotherapeutic Agents. New York: Columbia Univ. Press. 1949:191-205.

24 Coscarelli Shag C, Heinrich RL, Ganz PA. Karnofsky performance status revisited: reliability, validity and guidelines. J Clin Oncol 1984; 2: 187-193.

25 Mor V, Laliberte L, Morris J N, Wiemann M. The Karnofsky status scale: an examination of its reliability and validity in a research setting. Cancer 1984; 53: 2002-2007.

26 Barker FG, Prados MD, Chang SM, et al. Radiation response and survival time in patients with glioblastoma multiforme. J Neurosurg 1996; 84: 442-448.

27 Fine HA, Dear KBG, Loeffler JS, Black PM, Canellos GP. Metaanalysis of radiation therapy with and without adjuvant chemotherapy for malignant gliomas in adults. Cancer 1993; 71: 2585-2597.

28 Hildebrand J, Sahmoud T, Mignolet F, Brucher JM, Afra D, EORTC Brain Tumour Group. Adjuvant therapy with dibromodulcitol and BCNU increases survival of adults with malignant gliomas. Neurology 1994; 44: 1479-1483.

29 DeAngelis LM, Burger PC, Green SB, Cairncross JG. Malignant glioma: who benefits from adjuvant chemotherapy? Ann Neurol 1998; 44: 691-695.

30 Cairncross JG, MacDonald DR. Successful chemotherapy for recurrent malignant oligodendrogliomas. Ann Neurol 1988; 23: 360-364.

31 MacDonald DR, Gasper LE, Cairncross JG. Successful chemotherapy for newly diagnosed aggressive oligodendroglioma. Ann Neurol 1990; 27: 573-574.

32 Cairncross JG, MacDonald DR, Ludwin S, et al. Chemotherapy for anaplastic oligodendroglioma J Clin Oncol 1994; 12: 2013-2021.

33 Yung WKA, Prados MD, Yaya-Tur R, et al. Multicenter phase II trial of temozolamide in patients with anaplastic astrocytoma or anaplastic oligodendroglioma at first relapse. J Clin Oncol 1999; 17: 2762-2771.

34 Yung WKA, Albright RE, Olson J, et al. A phase II study of temozolamide vs. probarbazine in patients with glioblastoma multiforme at first relapse. Br J Cancer 2000; 83: 588-593.

35 Stupp R, Dietrich P, Kraljevic SO, et al. Promising survival for patients with newly diagnosed glioblastoma multiforme treated with concomitant radiation plus temozolomide followed by adjuvant temozolomide. J Clin Oncol 2002; 20: 1375-1382.

36 Mackworth N, Fobair P, Prados MD. Quality of life self-reports from 200 brain tumor patients: comparisons with Karnofsky performance scores. J Neurooncol 1992; 14: 243-253.

37 Weitzner MA, Meyers CA. Cognitive functioning and quality of life in malignant glioma patients: a review of the literature. Psychooncology 1997; 6: 167-177.

38 Aiken RD. Quality of life in patients with malignant gliomas. Semin Oncol 1994; 21: 273-275. 